\title{
A Lei Geral de Acumulação Capitalista: uma Análise a partir de um Modelo de Goodwin Modificado*
}

\section{The General Law of Capitalist Accumulation: an Analysis from a Modified Goodwin Model}

Resumo: A lei geral da acumulação é um tema recorrente nas pesquisas marxistas. Por outro lado, o modelo de Goodwin é várias vezes citado como uma tradução formal da lei geral no caso em que a composição orgânica é constante. Compreendendo que a acumulação capitalista com composição orgânica constante é apenas um caso particular, objetiva-se neste texto construir um modelo formal que incorpore a ideia de composição orgânica crescente.

Palavras-chave: Lei geral de acumulação. Composição orgânica. Modelo de Goodwin.

Abstract: The general law of accumulation is a recurring theme in Marxist studies. On the other side, the Goodwin model is several times referred to as a formal translation of the general law in the case where the organic composition is constant. Realizing that the capitalist accumulation with constant organic composition is just a particular case, the objective is to build in this paper a formal model that incorporates the idea of growing organic composition.

Keywords: General law of accumulation. Organic composition. Goodwin model.

JEL Classification: E11; E32; C62.

\section{Introdução}

Este é um trabalho sobre a lei geral da acumulação capitalista apresentada por Marx (1996) em O Capital. O capitalismo caracteriza-se como um sistema no qual a necessidade da acumulação é crescente. Em

\footnotetext{
* $\quad$ Agradeço os valiosos comentários dos(as) pareceristas anônimos que, como de praxe, estão isentos dos equívocos do autor.

** Mestrando em Desenvolvimento Econômico pelo Programa de Pós-Graduação em Desenvolvimento Econômico (PPGDE) da Universidade Federal do Paraná (UFPR) e bolsista CAPES. E-mail: carloseduardo.drumond@gmail.com
} 
outras palavras, os capitalistas são impelidos, dentro da própria lógica do Capital, a expandir a acumulação. A intensificação da acumulação produz efeitos sobre a vida dos trabalhadores na medida em que, desde que mantida constante a composição orgânica do capital, tende a aumentar a procura por força de trabalho e, no limite, os salários. No escopo deste texto, busca-se apresentar o modelo de Goodwin (a partir de um exercício de simulação) como aderente às ideias contidas na primeira parte do capítulo 23 do Capital, Livro I.

Vale salientar que o caso em que a acumulação ocorre com composição técnica inalterada é apenas um caso particular, existindo uma tendência inerente ao capitalismo em expandir a parcela relativa do capital constante. Neste sentido, é relevante estudar o caso mais geral apresentado por Marx (1996) na segunda parte do capitulo 23, ao mesmo tempo em que se empreende uma reformulação do modelo de Goodwin, no intuito de compatibilizá-lo com a ideia de composição técnica crescente.

A fim de cumprir os objetivos anteriormente apresentados, o presente texto divide-se da seguinte forma: a primeira seção apresenta a lei geral com composição constante e faz uma simulação numérica com o modelo de Goodwin original. Na segunda seção, empreende-se a apresentação do caso mais geral com composição crescente e nessa mesma seção são introduzidas modificações no modelo de Goodwin, sendo feitas as devidas simulações. Como de costume, as considerações finais encerram o texto.

\section{A Lei Geral com Composição Constante do Capital}

Um dos traços fundamentais do modo de produção capitalista é a necessidade contínua de geração de excedente, em outras palavras: "Produção de mais-valia ou geração de excedente é a lei absoluta desse modo de produção" (MARX, 1996, p. 251). Especialmente no capítulo 23 do Livro I do Capital, Marx (1996) constrói um exercício analítico, a fim de compreender a "Lei Geral da Acumulação Capitalista". Obviamente esse exercício não ocorre dissociado do âmbito geral da obra, de modo que a compreensão correta do capitulo 23 só é viável quando construída em consonância com as categorias fundamentais do pensamento marxiano. Por outro lado, respeitar o caráter totalizante da obra de Marx (1996) não significa evitar todo o tempo simplificações analíticas, afinal, é exatamente com uma simplificação que se inicia o capitulo sobre a "Lei Geral".

Ao debruçar-se sobre a chamada Lei Geral da Acumulação, Marx (1996) partiu de um caso particular em que a composição orgânica do capital (refletida na composição técnica) é constante. Vale ressaltar que 
não se trata da composição de capitais particulares, mas da composição global em certo país (reflexo das médias das composições orgânicas particulares).

Sob estas condições, e considerando também que a taxa de exploração não possa ser extrapolada além de certos limites, o processo crescente da acumulação capitalista representa crescimento de sua parcela variável, isto é, significa uma demanda crescente por força de trabalho. Com o capital expandindo-se de modo ampliado, como aponta Marx:

[...] as necessidades da acumulação do capital podem superar o crescimento da força de trabalho ou do número de trabalhadores, a demanda de trabalhadores pode se tornar maior que a sua oferta e por isso os salários se elevam. [...] Como a cada ano mais trabalhadores são ocupados do que no anterior, mais cedo ou mais tarde tem de se chegar ao ponto em que as necessidades da acumulação começam a crescer além da oferta habitual de trabalho, em que, portanto, começa o aumento salarial. (MARX, 1996, p. 246)

O aumento dos salários e, consequentemente, da participação do salário na renda, não muda o caráter intrínseco da acumulação, isto é, a finalidade precípua do capitalismo é a produção de mercadorias que possuam mais trabalho do que ela paga. Desta forma, a demanda crescente por força de trabalho pode representar melhoria relativa das condições de vida dos trabalhadores, mas isso só pode ocorrer na medida em que não comprometa o processo de acumulação.

Marx elenca duas possibilidades em um cenário como este: 1) mesmo com os lucros diminuindo (devido ao aumento relativo da participação dos salários na renda) os capitais continuam a aumentar. 2) ou a diminuição dos lucros, resultado da diminuição da parte não paga do trabalho, começa a atravancar o processo de ampliação do capital.

Os dois casos são possíveis, contudo, é plausível pensar que à medida que se exacerba o processo de aumento dos salários mais perto se estará da situação 2 . No caso disso ocorrer haverá uma reação por parte dos capitalistas:

[...] assim que essa diminuição (proporcional do trabalho não pago) atinge o ponto em que o mais-trabalho, que alimenta o capital, já não é oferecido na quantidade normal, então ocorre uma reação: uma parte menor da renda é capitalizada, a acumulação se desacelera e o movimento ascendente do salário sofre um contragolpe. (MARX, 1996, p. 253).

Mantidas inalteradas todas as condições apresentadas até então, a demanda por força de trabalho e os salários teriam, portanto, um 
comportamento cíclico. À medida que a demanda por força de trabalho se amplia, os salários também ampliam-se, implicando restrições a acumulação. Desta forma, a partir de certo ponto, a demanda por trabalho diminui como forma de reação dos capitalistas, causando redução dos salários e dando início ao novo ciclo.

\subsection{0 modelo de Ciclos de Goodwin}

A despeito das possíveis controvérsias sobre a filiação teórica de Goodwin, o próprio se definiu como um "[...] vitalício, porém rebelde marxista" (GOODWIN, 1983, tradução nossa). Seu conhecido modelo, apresentado no texto A Growth Cycle, parece ser uma representação formal aproximada das ideias apresentadas na seção anterior. Goodwin debruçou-se sobre o problema da repartição da renda entre salários e lucros, algo que foi desprezado pelo mainstream, mas que tem papel precípuo na obra de Ricardo, Smith e do próprio Marx, não sendo algo desprezível quando a intenção é compreender a dinâmica capitalista.

Um dos aspectos positivos dos esforços deste autor é a tentativa de compreensão da acumulação capitalista como um processo não linear, sujeito a complexidades negligenciadas pelo pensamento dominante. Não obstante, é importante conceber os limites deste modelo, sobretudo, tendo em vista as suas simplificações analíticas.

As equações fundamentais do modelo são as que seguem:

$$
\begin{aligned}
& \dot{x}=[-(\propto+\theta)+\beta y] x \\
& \dot{y}=\left[-\frac{x}{v}-(\theta+n)+\frac{1}{v}\right] y
\end{aligned}
$$

Em que:

$x=$ participação dos salários na renda

$-\propto=$ nível mínimo de salário real

$\theta=$ taxa constante de crescimento da produtividade

$n=$ taxa constante de crescimento da população

$\beta=$ elasticidade dos salários em relação ao nível de emprego

$y$ = nível de emprego

$v=$ razão capital produto 
As equações (1) e (2) formam um sistema de equações diferenciais não lineares, semelhante ao modelo predador presa de Lotka e Volterra, que explicita um comportamento cíclico da taxa de emprego e da participação dos salários na renda.

No estudo de modelos não lineares, como é o caso deste, soluções numéricas são bastante úteis para compreender as trajetórias das variáveis no tempo. Pode-se construir soluções numéricas com auxilio de softwares, ${ }^{1}$ para isso, é necessário atribuir valores aos parâmetros do modelo, assim como definir as condições iniciais das variáveis de estado $(x, y)$. Neste texto, optou-se por parametrizar o modelo com base na média dos valores estimados por Harvie (2000) para dez países da $\mathrm{OCDE}^{2}$ com dados do período 1954-1991.

Tabela 1 - Condições de Contorno

\begin{tabular}{ll}
\hline \multicolumn{2}{c}{ Condições iniciais das variáveis } \\
\hline $\mathbf{x}_{\mathbf{0}}$ & 0,60 \\
$\mathbf{y}_{\mathbf{0}}$ & 0,97 \\
Fonte: Elaborada pelo autor com base em Harvie (2000).
\end{tabular}

Tabela 2 - Valores dos Parâmetros

\begin{tabular}{ll}
\hline & Valores dos parâmetros \\
\hline$\propto$ & 55,600 \\
$\boldsymbol{\theta}$ & 0,028 \\
$\boldsymbol{\beta}$ & 64,040 \\
$\boldsymbol{n}$ & 0,011 \\
$\boldsymbol{v}$ & 2,590 \\
\hline
\end{tabular}

Fonte: Elaborada pelo autor com base em Harvie (2000).

Com base nos valores da tabela, procedeu-se a resolução numérica do modelo, utilizando o método de Runge-Kutta, com passo de integração $(\Delta t)$ igual a 0,1 e com 50 interações. Seguem as séries obtidas de participação dos salários na renda e da taxa de emprego.

$1 \quad$ Foi utilizado o Scilab 5.1.1 (software livre).

2 Austrália, Canadá, Finlândia, França, Alemanha, Grécia, Itália, Noruega, Inglaterra e Estados Unidos. 


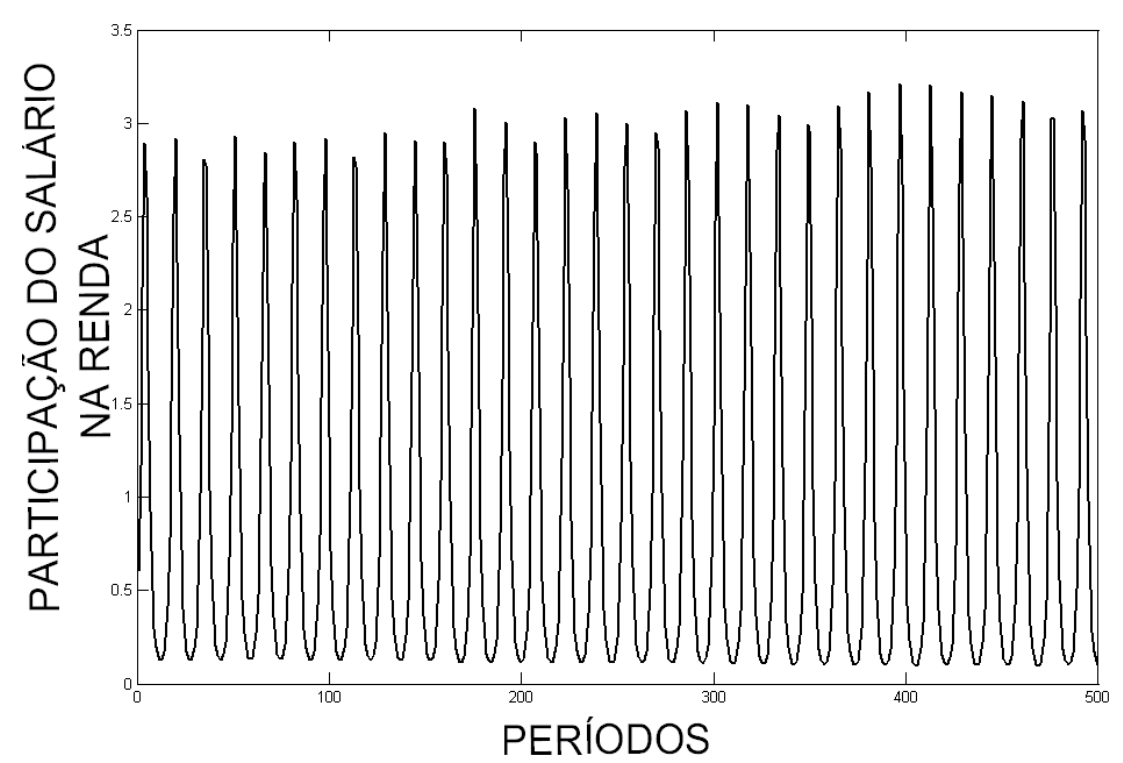

Figura 1 - Ciclo da participação dos salários na renda Fonte: Elaborada pelo autor.

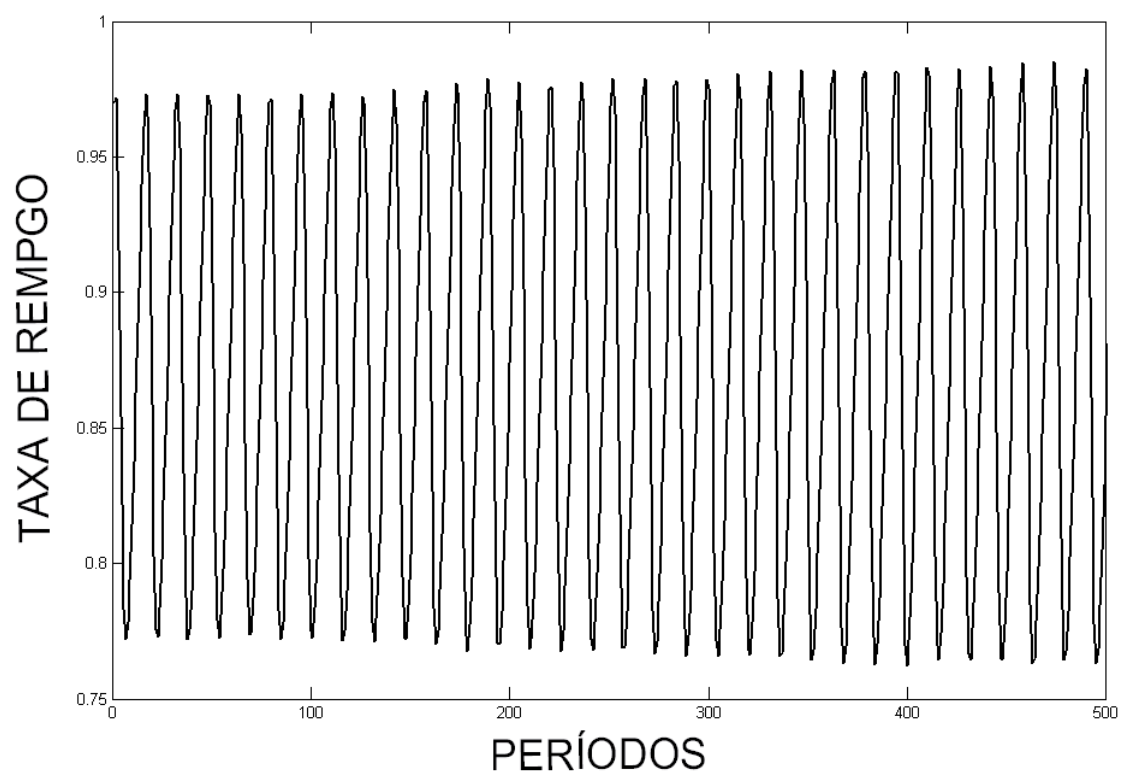

Figura 2 - Ciclo do emprego

Fonte: Elaborada pelo autor.

Como pode-se observar, a série da participação dos salários na renda apresenta uma anomalia, valores que ultrapassam a unidade, sendo que, por definição, deviam restringir-se ao intervalo entre 0 e 1. Como destacam Desai et al. (2006), esta é uma anomalia própria do modelo de Goodwin. O que se argumenta a favor do modelo, é que isso não compromete a análise qualitativa advinda deste. 


\section{Composição do Capital Crescente Decorrente do Decréscimo Relativo à Parte Variável do Capital}

A forma como a acumulação foi apresentada até agora é na verdade um caso particular, "[...] aquele em que o crescimento adicional de capital ocorre com composição técnica do capital constante." (MARX, 1996, p. 253). Na medida em que se intensifica a acumulação, tende a ocorrer aumento da produtividade do trabalho e uma massa relativamente menor de capital variável precisa ser mobilizada para uma dada quantidade de capital constante. A tendência à produção em larga escala com crescente cooperação e divisão do trabalho, assim como o uso de máquinas mais modernas, são elementos causadores do aumento relativo do capital constante, contudo nenhum destes movimentos ocorre de modo autônomo, deslocado da lógica da acumulação ou ligado a algum desejo idealista de melhoria da produção.

Mas todos os métodos de elevar a força produtiva social do trabalho, surgidos sobre esse fundamento, são, ao mesmo tempo, métodos de elevar a produção de mais-valia ou mais-produto, que, por sua vez, é o elemento constitutivo da acumulação. (MARX, 1996, p. 256).

O modelo de Goodwin em sua forma original não abarca o caso mais geral apresentado em Marx (1996), i.e., o caso em que a composição técnica do capital é crescente. ${ }^{3} \mathrm{Na}$ realidade o modelo não faz menção explicita à composição, contudo deixa evidente que a relação capital-produto é invariável ao longo do tempo, o que logicamente significa uma relação invariável entre capital constante e variável. "Até agora examinamos apenas uma fase particular desse processo, aquela em que o crescimento adicional de capital ocorre com composição técnica do capital constante. Mas o processo ultrapassa essa fase" (MARX, 1996, p. 253). Uma forma de tornar o modelo mais aderente à teoria marxista é evidenciando a composição técnica e fazendo com que ela não seja invariável ao longo do tempo.

O estudo do Capital leva a crer que existe uma necessidade intrínseca da acumulação capitalista de utilização crescente de capital constante, esse movimento ocorre tanto no interior de cada capital individual como no capital em geral, e é intensificado pelo processo da concorrência e de concentração.

3 Neste caso não se considera a possibilidade de crescimento da produtividade no setor que produz bens de capital, o que traria consequências para a composição orgânica em termos de valor. 
A tendência em direção à mecanização é, portanto, o método capitalista dominante para aumentar da produtividade social do trabalho. Ele surge do controle que o capitalista exerce sobre o processo de trabalho, sobre a atividade humana produtiva. [...] O aumento da mecanização dá origem ao que Marx chama de um aumento na composição técnica do capital. Quantidades cada vez maiores de meios de produção e materiais são postos em operação por um determinado número de trabalhadores. (SHAIKH, 1983, p. 31).

O exercício seguinte visa a incorporar a hipótese de composição técnica crescente ao modelo e analisar seus resultados.

\subsection{Um modelo de Goodwin Modificado}

Na seção 2.1, não foi apresentada a derivação detalhada do modelo, considerando tratar-se de uma formalização conhecida, cuja importância maior encontra-se em suas equações finais. Nesta seção, ao contrário, é importante resgatar a derivação formal da equação do emprego (equação 2) visto que, é nela que vão se operar as modificações.

Chamando o lucro de $P$, tem-se a seguinte equação:

$$
P=Y-w L
$$

Em que $Y$ é o produto total e $w L$ é a massa salarial da economia. Dividindo ambos os lados da equação por Y, ter-se-á a participação dos lucros na renda.

$$
\begin{aligned}
& \frac{P}{Y}=1-\frac{w L}{Y} \\
& \frac{P}{Y}=1-x
\end{aligned}
$$

Sendo que $\frac{w L}{Y}$ é a participação do salário na renda, chamada de $x$. Uma hipótese fundamental é que os capitalistas investem todos os seus lucros:

$$
P=I=\dot{K}=Y-w L=Y(1-x)
$$

Em que $I$ é o investimento, igual à variação do capital fixo $K$ no tempo. Dividindo a equação (5) por $K$, é possível encontrar a taxa de variação do capital constante no tempo:

$$
\frac{\dot{K}}{K}=\frac{Y}{K}(1-x)
$$


Tem-se que $K / Y$ é a razão capital produto igual $v$.

$$
v=\frac{K}{Y}, \quad \frac{\dot{K}}{K}=\frac{1}{v}(1-x)
$$

No modelo original, essa relação é tida invariável, contudo, neste caso, considera-se que $v$ seja uma função da composição técnica do capital $c$. Chamando $K / L$ de $c$, e $L / Y$ de $1 / \lambda$ tem-se:

$$
\begin{gathered}
v=\frac{K}{L}\left(\frac{L}{Y}\right) \\
v=\frac{c}{\lambda}
\end{gathered}
$$

Conserva-se a hipótese do modelo original de produtividade do trabalho crescente a uma taxa constante, isto é, $\lambda=\frac{Y}{L}$ e $\frac{\lambda}{\lambda}=\theta$. Posto isto, a taxa de variação de $v$ no tempo é descrita pela equação (10).

$$
\frac{\dot{v}}{v}=\frac{\dot{c}}{c}-\theta
$$

Levando em conta que existe um elemento intrínseco do capital que alavanca a composição técnica, definir-se-á a taxa de crescimento da composição técnica como uma variável "z" ${ }^{4}$ Objetiva-se apreender com essa variável o processo crescente de mecanização da produção capitalista.

$$
\begin{aligned}
& \frac{\dot{c}}{c}=z, \\
& \frac{\dot{v}}{v}=z-\theta
\end{aligned}
$$

Sabe-se que $v=\frac{K}{Y}$ então $K=v Y$, derivando em logaritmos naturais:

$$
\frac{\dot{K}}{K}=\frac{i}{v}+\frac{\dot{Y}}{Y}
$$

4 Por hipótese esta variável é constante e exógena. 
Substituindo (13) em (7):

$$
\begin{aligned}
& \frac{\dot{v}}{v}+\frac{\dot{Y}}{Y}=\frac{1}{v}(1-x) \\
& \frac{\dot{Y}}{Y}=\frac{1}{v}(1-x)-\frac{\dot{v}}{v}
\end{aligned}
$$

Como $Y / L$ cresce a taxa $\theta$ :

$$
\frac{\dot{Y}}{Y}-\frac{\dot{L}}{L}=\theta
$$

Logo:

$$
\frac{\dot{L}}{L}=\frac{1}{v}(1-x)-\frac{\dot{v}}{v}-\theta
$$

Tem-se que o emprego é dado por:

$$
y=\frac{L}{N}
$$

Em que $L$ é o número de trabalhadores empregados e $N$ o número total de trabalhadores. A hipótese do modelo é que o número de trabalhadores totais cresce a uma taxa $n$ igual à taxa de crescimento da população, assim, colocando em termos de taxas de crescimento:

$$
\frac{\dot{y}}{y}=\frac{\dot{L}}{L}-n
$$

Combinando (17) e (16):

$$
\frac{\dot{y}}{y}=\frac{1}{v}(1-x)-\frac{\dot{v}}{v}-\theta-n
$$

Substituindo (12) em (18) tem-se a nova equação da variação do emprego, gerando um modelo modificado por composição técnica crescente.

$$
\begin{gathered}
\dot{v}=(z-\theta) v \\
\dot{y}=\left[\frac{1}{v}(1-x)-z-n\right] y
\end{gathered}
$$


Há agora um sistema de equações diferenciais formado pelas equações (19), (20) e (1). Note que não foram feitas modificações na equação dos salários:

$$
\begin{aligned}
& \dot{x}=[-(\propto+\theta)+\beta y] x \\
& \dot{y}=\left[\frac{1}{v}(1-x)-z-n\right] y \\
& \dot{v}=(z-\theta) v
\end{aligned}
$$

Como já fora explicitado, é bastante útil utilizar simulações numéricas para analisar modelos não lineares. Serão mantidas as condições iniciais das variáveis como apresentadas nas tabelas 1 e 2, contudo, como $v$ deixou de ser parâmetro e tornou-se variável, seu valor paramétrico torna-se o valor inicial. Quanto à taxa de crescimento da composição técnica, far-se-ão três suposições: 1) taxa de crescimento da composição técnica é pequena e igual ao crescimento da produtividade do trabalho $(\mathrm{z}=0,028) ; 2)$ taxa de crescimento da composição técnica intermediária $(\mathrm{z}=0,06)$; e 3) taxa de crescimento da composição técnica intensa $(\mathrm{z}=0,08)$.

\section{Caso 1 - Taxa de crescimento da composição pequena}

Neste caso, o ciclo da participação dos salários na renda e o ciclo do emprego têm comportamento semelhante ao modelo de Goodwin original, i.e., ciclos sem tendência à estagnação do processo de acumulação.

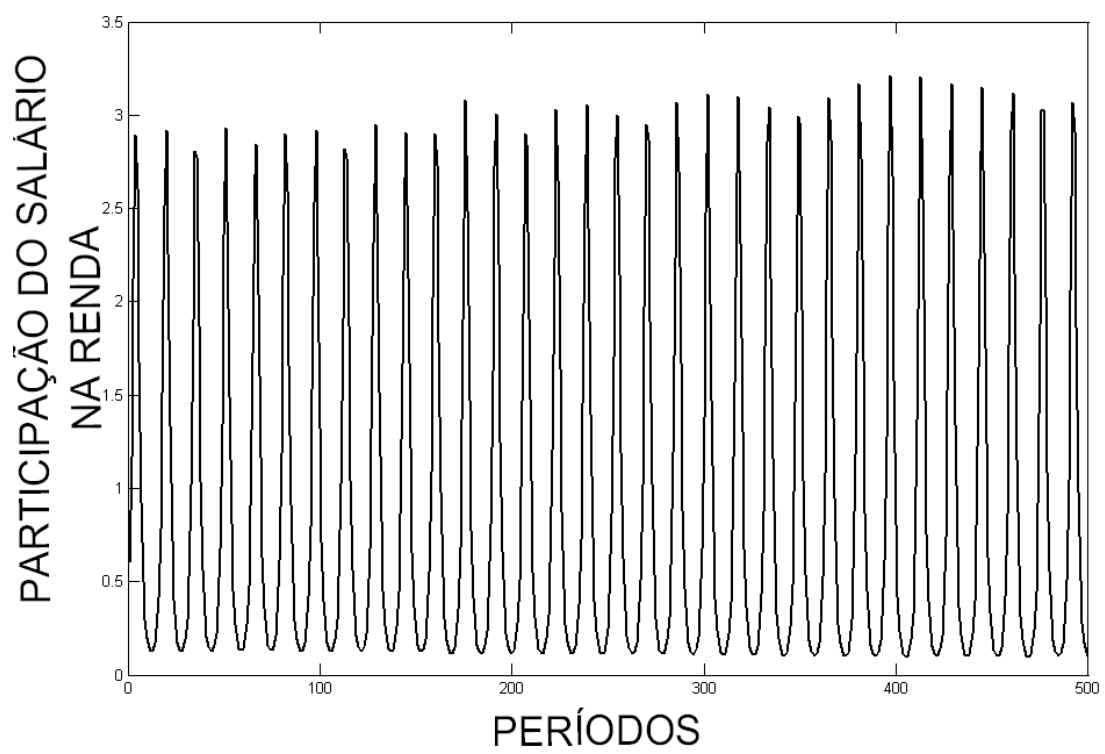

Figura 3 - Ciclo da participação dos salários na renda (Caso 1) Fonte: Elaborada pelo autor. 


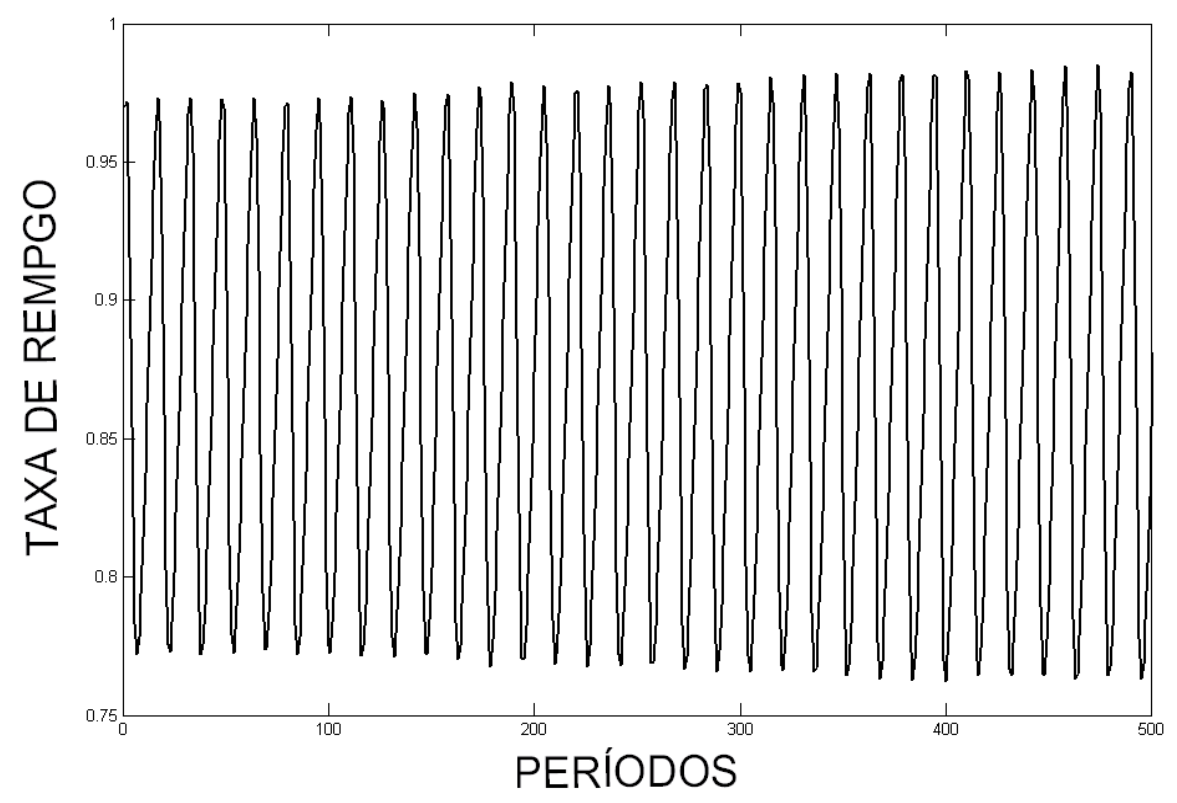

Figura 4 - Ciclo do emprego (Caso 1)

Fonte: Elaborada pelo autor.

Caso 2 - Taxa de crescimento da composição intermediária

Neste caso, os ciclos são mais conturbados e tanto a participação do salário na renda quanto o emprego tendem à estagnação no longo prazo, o que em termos marxistas poderia ser identificado com a tendência hodierna do capitalismo em produzir contraditoriamente seus limites. Cabe salientar que o ciclo dos salários tende a estagnar mais rapidamente que o do emprego, ${ }^{5} \mathrm{em}$ outras palavras, a distribuição de renda piora com maior velocidade do que as taxas de emprego.

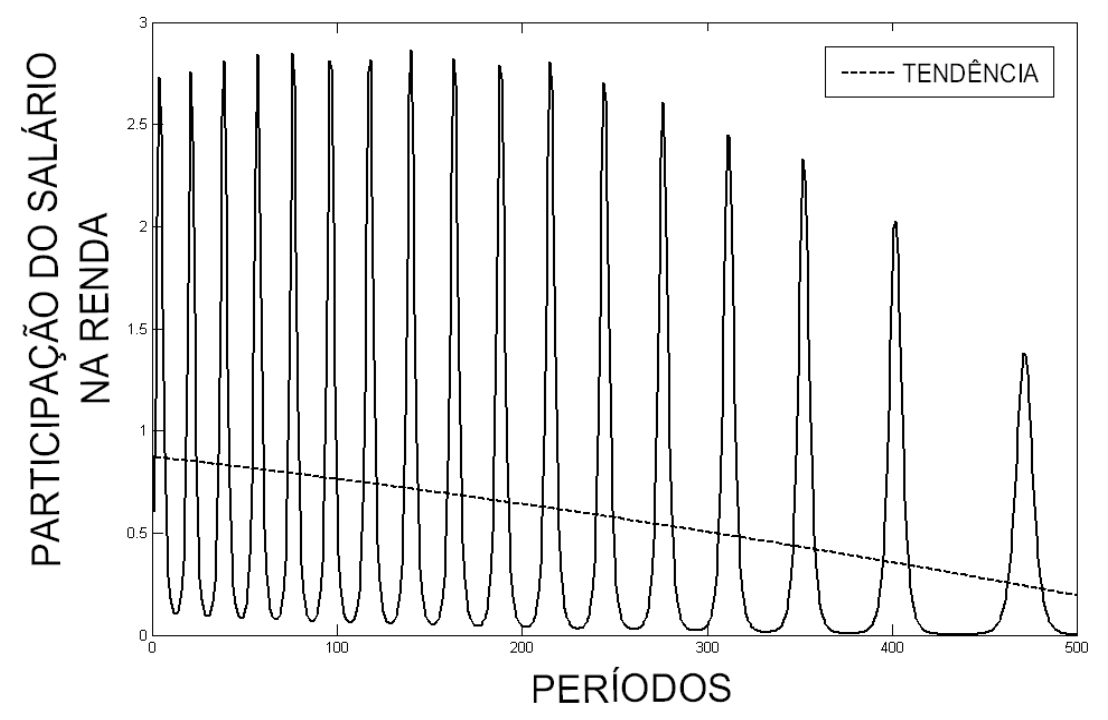

Figura 5 - Ciclo da participação dos salários na renda (Caso 2) Fonte: Elaborada pelo autor. 


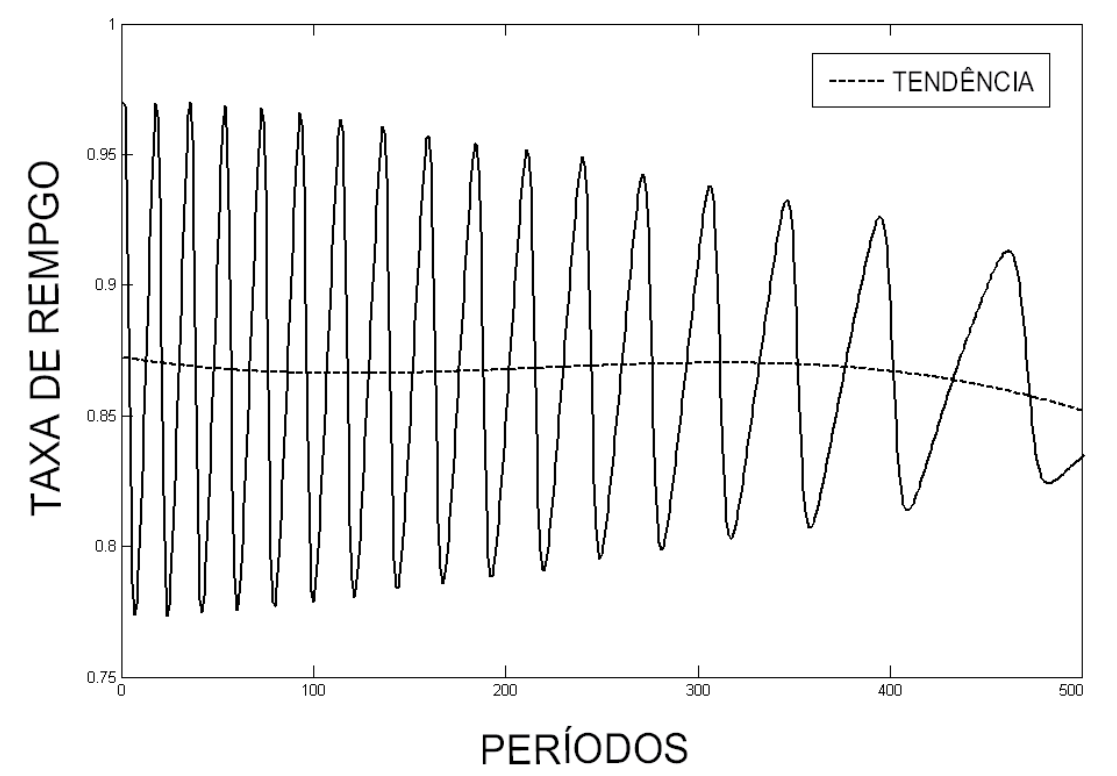

Figura 6 - Ciclo do emprego (Caso 2)

Fonte: Elaborada pelo autor.

Caso 3 - Taxa de crescimento da composição intensa

No último caso, a tendência à estagnação do processo de acumulação (expressa nos ciclos do emprego e da participação dos salários na renda) é mais intensa, de modo que em menos períodos a economia do modelo chega ao seu limite.

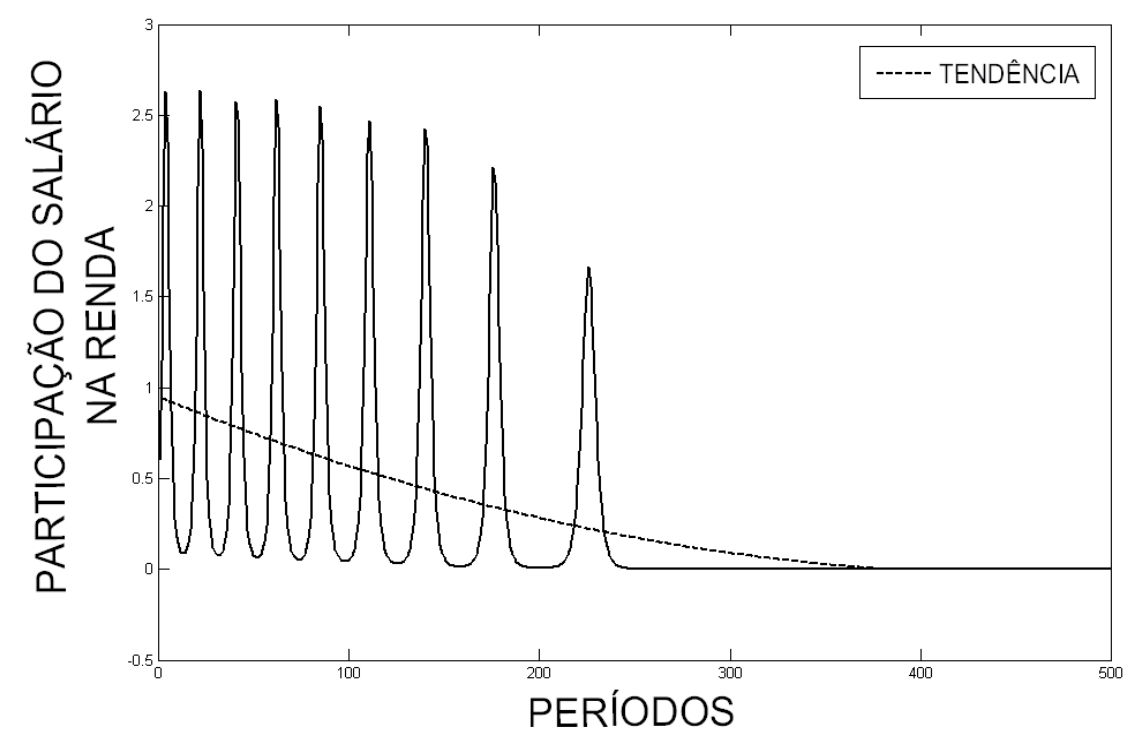

Figura 7 - Ciclo da participação dos salários na renda (Caso 3) Fonte: Elaborada pelo autor. 


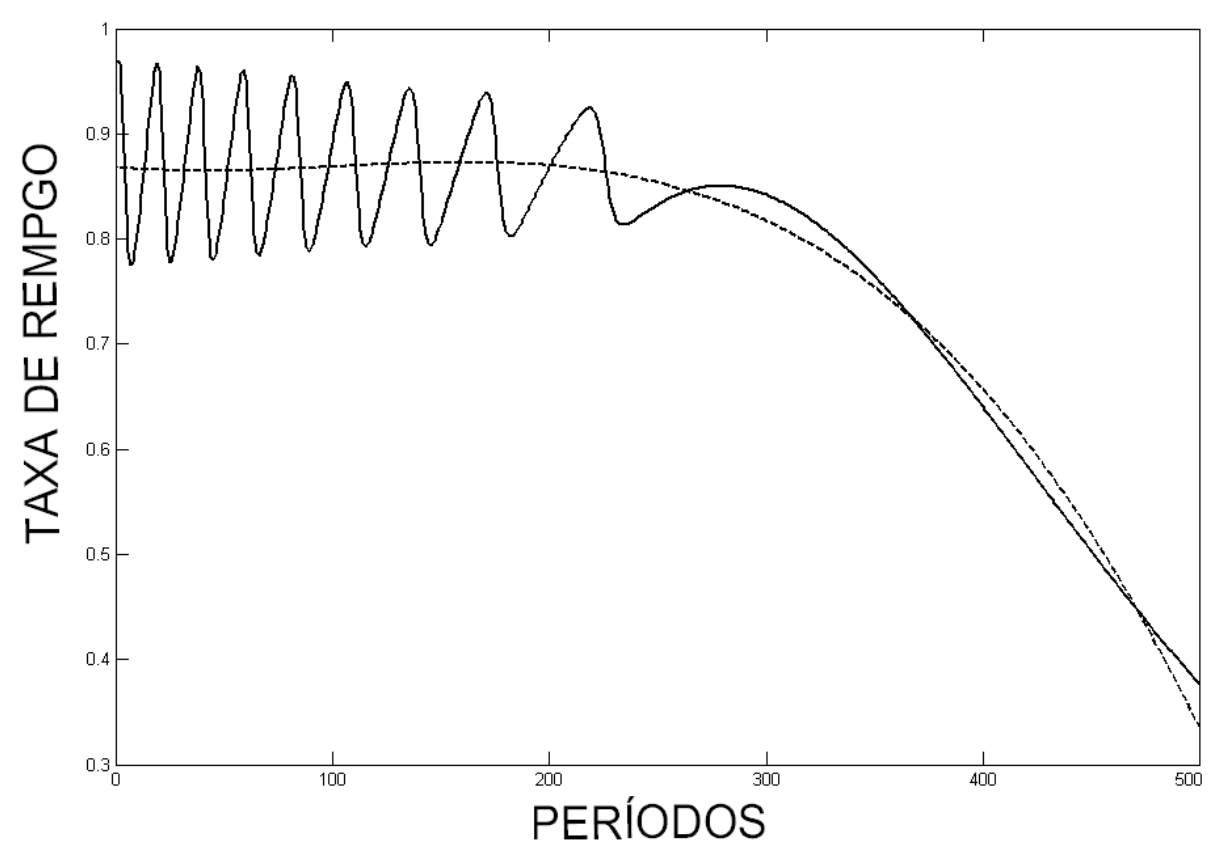

Figura 8 - Ciclo do emprego (Caso 3)

Fonte: Elaborada pelo autor.

\section{Considerações Finais}

O modelo de Goodwin na sua forma original parece ser uma boa aproximação do caso particular da lei geral da acumulação exposta por Marx. Contudo, a composição orgânica (expressa na composição técnica) tende a extrapolar o caso particular de composição invariável, sendo uma característica mais geral da acumulação capitalista aumentar a parcela relativa de capital constante. O exercício proposto de modificação do modelo de Goodwin oferece soluções interessantes, no que se refere à acumulação em sua forma mais geral, cuja principal conclusão analítica é que, conforme a composição técnica cresce a taxas maiores, mais rapidamente a economia tende à estagnação. Uma ideia fundamental do pensamento de Marx diz respeito ao fato do capitalismo possuir em suas entranhas a própria semente de seu esgotamento, pois, se por um lado o crescimento da composição orgânica é condição fundamental para acumulação, este próprio elemento traz consigo efeitos deletérios para o Capital.

Evidentemente todo exercício formal está sujeito a limites bastante estreitos, de modo que o significado teórico de um modelo como o aqui exposto só tem consistência se correlacionado com elementos mais pro- 
fundos da teoria. No que diz respeito ao programa de pesquisa marxista existem inúmeras interpretações sobre o processo cíclico do capital e das teorias de crise. ${ }^{6}$ Obviamente conforme abrir-se a análise e elementos da totalidade forem apreendidos, melhores resultados serão obtidos.

\section{Referências}

DESAI, M. et al.. A clarification of the Goodwin model of the growth cycle. Journal of Economic Dynamics and Control, v. 30, n. 12, p. 2661-2670, 2006.

DESAI, M.; SHAH, A. Growth cycles with induced technical change. The Economic Journal, v. 91, n. 364, p. 1006-1010, dec., 1981.

GOODWIN, R. M. A growth cycle. In: FEINSTEIN, C. H. (Ed.). Socialism, capitalism and economic growth. London/New York: Cambridge University Press, 1967.

. Essays in linear economic systems. London: Macmillan, 1983.

HARVIE, D. Testing goodwin: growth cycles in ten OECD countries. Cambridge Journal of Economics, v. 24, n. 3, p. 349-376, 2000.

MARX, K. O Capital: crítica da economia política. São Paulo: Nova Cultura, 1996. Tomo 2.

SHAIKH, A. Uma introdução à história das teorias de crises. Porto Alegre: Ensaios FEE, 1983.

VIANA, L. V. Introdução à dinâmica não linear e caos em economia. Mimeo, 2009.

Recebido: 11/03/2010.

Aceito: 04/08/2010.

6 Ver Shaikh (1983). 